\title{
The Use of Phonetically Reduced Modals in Present-day English: A Corpus-Based Analysis
}

\author{
Ikmi Nur Oktavianti \\ Universitas Ahmad Dahlan \\ ikmi.oktavianti@pbi.uad.ac.id
}

\begin{abstract}
This paper examines the usage frequency of phonetically reduced modals (i.e. gonna, wanna, gotta) in Present-day English. It is assumed that in distinct sociolinguistic and discourse contexts, the use of reduced modals is dynamic. To collect the data, there are five corpora used in this study, Corpus of Contemporary American English and Global WebBased English as the representatives of Present-day English, Brown and LOB corpus as the representative of earlier years of Present-day English, and A Representative Corpus of Historical English to provide language data from Early Modern English to Present-day English. The analysis focuses on usage frequency of phonetically reduced modals over period of time, in different regions or countries, different medium of language use, and different text categories. The frequencies were further interpreted based on sociolinguistics and text category perspective to reveal the factors triggering the dynamic of use. The results of this study show the use of reduced modals is dramatically escalating in the last decades. According to regional observation, the use of reduced modals is more frequent in the United States than in other English-speaking countries. In relation to medium of language use, reduced modals are more commonly used in spoken language than in written language. As for text category, the usage frequency of reduced modal in fiction texts is the highest compared to academic texts and news texts. Academic texts seem to avoid these linguistic units since this sort of text must obey the use of standard language in which reduced forms are less standard and more colloquial. This phonetic reduction is plausible to occur since language system and language use apply economy principle. The use of phonetically reduced modals, however, varies in different context and is influenced by colloquialization: the more colloquial the context, the more frequent the use of reduced modals. In general, language use is phonetically simplified and sociolinguistically colloquialized.
\end{abstract}

Keywords: phonetically reduced modals, corpus, sociolinguistics, discourse, economy

How to Cite: Oktavianti, I. N. (2018). The use of phonetically reduced modals in presentday English: A corpus-based analysis. English Language Teaching Educational Journal, 1(3), 134-148.

\section{INTRODUCTION}

As a linguistic unit, modals are of paramount importance because in everyday life people not only talk about truth, but they also express possibility, necessity, or prediction-something that is non- or contra-factual or known as modality (Lyons, 1977; Palmer, 2001). It is thus likely to notice the use of modals in everyday life. As of 2017, the use of modals (from 1990-2017) compiled in Corpus of Contemporary American English (COCA) is 12.451 per 
one million words or it is $1,2 \%$ of the total size of the corpus. Although, compare to other functional elements such as article the or preposition in, the number is still negligible.

Apart from the statistical fact, English modals are always interesting to examine as they can be studied using various perspectives, such as the grammatical aspects (see Quirk, et al., 1985), semantic aspect (Chapin, 1973; Coates and Leech, 1980; Perkins, 1982; Coates, 1983; Collins, 2009; de Haan, 2012; among others), pragmatics and discourse (MacFarlan, 2013; Rubinstein, 2012; Facchinetti, 2013; Hardjanto, 2016; Adepujo, 2016), diachronic analysis (see Brinton, 1991; Krug, 2000; Biber, 2004; Millar, 2009; Leech, et al., 2009; Seggewiß, 2012; Lorenz, 2013; Collins, 2014), and corpus-based analysis (Francis and Kučera, 1982; Kennedy, 1992; Kennedy, 1998; Biber, et al., 1999; Oktavianti, 2016; among others). Investigating modals, however, is not an easy task. Holmes (1988) states that studying modals is fairly problematic, even for the native speakers of English, let alone for non-native speakers. One modal enables multi-interpretation, depends on the contexts. In other words, modal meaning is pragmatically challenging to study. As an example, Huddleston (1971) describe six (pragmatic) meanings of may, such as may that might express (1) qualified generalization, (2) exhaustive disjunction, (3) uncertainty, (4) guarantee, (5) legitimation, and (6) ability. Regarding the dynamic condition of the society using modals and the compelling aspect of modals, hence the study of English modals remains appealing over time, as long as language is used.

In regard to form, besides having the full forms, some modals - the periphrastic ones - are shortened, for instance be going to into gonna, have got to into gotta, and want to into wanna. While the full forms remain dominant in language practice, the use of reduced forms is growing in the last decades. It is believed that in the era of World Englishes, the use of reduced modals becomes more dynamic and significant. There have been some studies conducted to analyze these linguistic units, such as Leech, et al. (2009) and Machova (2015) using different corpora as data sources or different perspectives of analysis.

This study, however, focuses on the use of phonetically reduced modals (sometimes it is called 'reduced modals' in this paper) in Present-day English, in five different English-speaking countries, between two mediums of language use, and among three most popular text categories. Nevertheless, this paper, will leave the discussion on meaning as it has gained so much attention lately and due to its multi-interpretations, and delimit the analysis to frequency of use and the sociolinguistic and discourse-related discussion. This study is expected to provide preliminary investigation of reduced modal use in Present-day English so the results of the study can be used as teaching materials in linguistics classes (e.g., sociolinguistics and discourse analysis) as well as a reference for further profound studies. 


\section{Corpus Linguistics and Language Use}

This study uses both corpora and sociolinguistics as they work hand in hand to describe language use. Both corpus linguistics and sociolinguistics deal with 'real' language use, and are not based on researcher's introspection (Baker, 2010: 8). Using corpus enables more empirical approach and provides richer data to the sociolinguistic analysis. In addition, using corpus can lead to faster and more accurate analysis of frequency of use in which frequency is the key analysis of corpus linguistics (Biber, et al., 1998) and also an important discussion in sociolinguistics.

Observing language use, it is also necessary to take notes on the medium of language use as well as types of text produced, including the use of reduced modals. As explained by Halliday (1990), spoken medium and written medium have their distinct characteristics in the way spoken language rely much on prosodic and paralinguistic aspect in delivering messages. On the contrary, written language differs from spoken language since the process of production is not spontaneous and revision is thus permitted (Biber and Conrad, 2009). Regarding text categories, it is known that each text has its linguistic characteristic. News texts and academic texts basically share something in common: delivering information. The more detail characteristics, however, differ since academic texts also develop arguments and analysis scientifically (Biber and Conrad, 2009). Fiction is distinguished from two previous text categories because it uses language esthetically and manipulatively to build up imaginary world (Leech and Short, 2007). The different characteristics of each text category might result in different choices of linguistic units, including the use of phonetically reduced modals.

\section{RESEARCH METHOD}

One of the corpora consulted in this study is a synchronic corpus, COCA, to depict the frequency of use of phonetically reduced modals. COCA (Davies, 2008) comprises English language data from enormous and various sources, consisting of more than 560 million words, ranging from 1990 to 2017 data compilation. Along with COCA, another corpus, Global Web-Based English (GloWbe) is used to assist the analysis of use in different English-speaking countries. GloWbe compiles English language data, taken from the Internet, from 20 regional dialects of English, and consisting of 1,9 billion words. Following Leech (1993), to select representative corpus to assist English language analysis, three points need to be taken into account, including size of the corpus, the homogeneity of the sources, and data collection technique. COCA as the primary corpus has fulfilled two criteria (i.e. the size and homogeneity - in the subcorpus) and GloWbe has fulfilled one criterion (i.e. the size). Some other secondary corpora are used to provide evidence, namely Brown Corpus, LOB Corpus (both compiling English language data in 1961), and A Representative Corpus of Historical English Registers (ARCHER) that 
comprises English language from Early Modern English Period (1600) to the earlier years of Present-day English (1990).

The data of this study are frequencies of gonna, wanna, and gotta in COCA, GloWbe, Brown, LOB, and ARCHER. The data were collected through corpus query in online sites of COCA, GloWbe, ARCHER and using a corpus tool, Lancsbox (Brezina, et al., 2015), for Brown and LOB. All the reduced modals were searched in the corpora and the search itself was filtered using PoS (Parts of Speech) tag to limit the search, although gonna, wanna, and gotta are not likely to serve as other word classes in different syntactic environment. Once the data were collected, they were normalized (McEnery and Hardie, 2012; Brezina, 2018). The normalized frequencies (nf) were then interpreted using sociolinguistic and discourse perspectives in order to elaborate the factors triggering the dynamic of use in different sociolinguistic and discourse context.

\section{FINDINGS AND DISCUSSION}

The Nature of Modals and Phonetically Reduced Modals in Present-day English

Modals are semantic (and pragmatic) means to manifest modality expression in propositions (Payne, 2011). Historically they were derived from lexical categories (lexical verbs, preterite-present verbs), yet they were being grammaticalized into more functional elements and now they differ from lexical verbs. The changes result in distinct morphosyntactic and syntactic properties of modals and lexical verbs (Collins, 2009: 112; Warner, 2009). The features that distinguish modals from lexical verbs are described as NICE (Negation, Inversion, Code, Emphasis) (Huddleston, 1976; Warner, 2009; Payne, 2011) or also known as Auxiliaryhood (Pullum and Wilson, 1977), stating that modals can be negated, inversed, used in tag question and emphasized directly, without the assistance of operator do. In addition, morphosyntactically modals are not tense-inflected. Their preterite forms do not necessarily indicate past tense. Meanwhile, syntactically modals can only be followed by infinitive verbs in clauses or sentences.

According to Quirk, et al. (1985), modals are classified into central modals, marginal modals, idiom modals, and semi-auxiliaries. Some other experts, however, classify modals in a more simplified way by dichotomizing: (1) modals and semi modals (Leech, et al., 2009), (2) modals and quasi-modals (Collins, 2009), and (3) plain-modal auxiliaries and semi-auxiliaries (Payne, 2011). Based on the classification, it is noticed that basically there are two major types of modals; they are 'pure' modals or central modals or core modals (e.g., must, will, would, can, could, shall, should, may, might) and periphrastic or phrasal forms equivalent to 'pure' modals or known as semi-modals or quasi-modals (e.g., be going to, have to, be able to, be supposed to, want to, etc.).

In relation to human nature in minimalizing their efforts in doing something (principle of least effort, [Zipf, 1949]), including in using language, some periphrastic forms, especially the frequent ones such as be going to or 
want to are shortened or phonetically reduced. Bussmann (1998) claims that phonetic reduction happened to some quasi-modals is the effort to minimalize sound articulation and adjust it according to the phonetic environment. Sound change of be going to and want to into (be) gonna and wanna are illustrated below.

$$
\begin{array}{lc}
\text { (be) going to [gəoin tu:] } & \square \square \text { gonna ['gpnə] } \\
\text { want to [wont tu:] } & \square \square \text { wanna ['wDnə] }
\end{array}
$$

The illustration shows that the phonetic change alters velar consonant $[\mathrm{g}]$ in going to into alveolar consonant [n]. This is plausible since alveolar is closer to the mouth or outer part of our vocal tract so the effort to produce the sound is more minimal. As stated by Jakobson (1980) the outer the vocal tract used to produce the sound, the easier to pronounce the sound, as in bilabials sounds that are easier to produce by $6-9$ month old babies in babbling stage. As for [t] sound in want to is omitted to simplify the pronunciation to make the production effort minimal. Unlike gonna and wanna, gotta doesn't undergo consonant change, but vowel change, despite the deletion of have in the initial position, as in below.

$$
\text { (have) got to [gpt tu: } \quad \square \quad \text { gotta ['gptə] }
$$

The vowel change can be precisely depicted below.

\begin{tabular}{lll}
\multicolumn{1}{c}{$[\mathrm{u}:]$} & $\rightarrow$ & {$[\ni]$} \\
[back vowel] & & {$[$ central vowel] } \\
[low vowel] & {$[$ mid vowel] } \\
[rounded vowel] & {$[$ unrounded vowel] }
\end{tabular}

The changes from [u:] $\rightarrow$ [ə] as illustrated above seem to clearly show that there is an effort to minimize the 'energy' to produce the sound (from back to central, from low to mid, from rounded to unrounded). By minimizing the effort, language users can produce more utterance; hence deliver more messages or information.

\section{Phonetically Reduced Modals in Diachronic Corpora}

Based on the comparison of a diachronic corpus, ARCHER, and a synchronic corpus, COCA, it is found that there are two reduced modals occupying the first and the fourth position of modal usage frequency. Modals gonna and wanna undergo the most significant increase along with other quasimodals (be willing to, have got to, be due to), as listed in the following table (using normalized frequency per one million words). 
Table 1. Modals with the Most Significant Increase of Usage (ARCHER and COCA)

\begin{tabular}{lllll}
\hline Rank & Modals & ARCHER (nf) & COCA (nf) & $\begin{array}{l}\text { Percentage } \\
\text { change } \\
+1,833 \%\end{array}$ \\
1 & gonna & 3 & 58 & $+1,400 \%$ \\
2 & be willing to & 15 & 41 & $+1,400 \%$ \\
3 & have got to & 4 & 60 & $+1,292 \%$ \\
4 & wanna & 0.79 & 11 & $+1,100 \%$ \\
5 & be due to & 1 & 12 & \\
\hline
\end{tabular}

Table 1 shows the percentage change (see Brezina, 2018) of modals over decades in which the usage frequency of gonna is the highest by having 1,833\% change from Early Modern English (represented by ARCHER) to Present-day English (represented by COCA). Similarly, the use of wanna is increasing as much as $1,292 \%$. To get more convincing evidence, this study displays the frequency of use of reduced modals in two corpora covering the earlier years of Present-day English, namely LOB Corpus and Brown Corpus.

Table 2. Usage Frequency of Reduced Modals in LOB and Brown

\begin{tabular}{lll}
\hline Reduced modals & LOB & Brown \\
gonna & 0.02 & 0.06 \\
wanna & 0.03 & 0.05 \\
gotta & 0.02 & 0.05 \\
\hline
\end{tabular}

Table 2 presents normalized frequency of use of gonna, wanna, and gotta per ten thousand words in LOB and Brown corpus. The table clearly exhibits the low frequency of the reduced modals at the time. Meanwhile, ARCHER and COCA comparison shows the dramatic escalation of gonna and wanna. Therefore, it is assumed that in the last decades use of reduced forms of modals has gained much attention among English speakers. It is therefore compelling to conduct further investigation on the use of reduced forms of modals, focusing on gonna, wanna, and gotta.

\section{Usage Frequency of Phonetically Reduced Modals across Countries}

Using GloWbe, this study analyses phonetically reduced modals in English language spoken in the United States (US), Great Britain (GB), Australia (AU), Canada (CA), and New Zealand (NZ) that belong to inner circle position in world Englishes (Kachru, 2008). The normalized frequencies of the modals are shown in the following table. 
Table 3. Frequency of Reduced Modals in Five English-Speaking Countries

\begin{tabular}{llllll}
\hline Modals & US & GB & AU & CA & NZ \\
gonna & 54 & 25 & 20 & 22 & 14 \\
gotta & 21 & 7 & 7 & 13 & 8 \\
wanna & 21 & 9 & 9 & 8 & 6 \\
\hline
\end{tabular}

Table 3 presents that among five English-speaking countries, it is obvious that reduced modals used in US that has the highest frequency (e.g., 54 times per one million words for gonna), followed by Great Britain, Canada, Australia, and New Zealand (with the results show only half of the normalized frequency of the US). Compared to other countries displayed in the table, English used in New Zealand has the lowest frequency of reduced modals usage. This result basically supports some other similar or relevant findings. Collins (2014) claims there have been some tendencies in relation to English language changes. It is proved that, based on Collins (2014), American English is more adjustable to changes, while British English is more conservative. Meanwhile, according to Collins (2014), Australian English is more linguistically independent, not too conservative as the colonial parent (British English), but not too loose as American English. The most important point to notice here is the state of English spoken in the US as the leader of changes of English language. The discussion of it hence needs to be elaborated in a different and more comprehensive work.

\section{Usage Frequency of Phonetically Reduced Modals in Spoken and Written English}

The next discussion is about the medium of language use. Considering that spoken and written language are distinct, it is also intriguing to depict the reduced modal usage in these two media of using language. The table below shows the normalized frequency of gonna, wanna, and gotta in spoken and written English (as compiled from COCA).

Table 4. Frequency of Reduced Modals in Spoken and Written English

\begin{tabular}{lll}
\hline Modals & Spoken & Written \\
gonna & 132 & 37 \\
wanna & 25 & 7 \\
gotta & 11 & 16 \\
\hline
\end{tabular}

Table 4 shows the differences observed such as the use of gonna and wanna that are extremely different in these two contexts. In spoken English, gonna is found 132 times per one million words, while in written English it is found only 37 times per one million words. Similar to gonna, wanna is also found more frequent in spoken English (25 times per one million words) than 
in written English (7 times per one million words). It proves that spoken and written English are different, resulting in different choice of linguistic units used by the speakers. Hence,g the use of reduced modals in spoken English differs from that in written English.

\section{Usage Frequency of Phonetically Reduced Modals in Different Text Categories}

The context in which the language is used to determine the linguistic choice, including the choice of using reduced modals. In written language, text categories hold a crucial part in deciding whether or not to use reduced modals. Pivoting in fiction, academic, and news texts, below is the description of normalized frequency in these text categories as observed in COCA.

Table 5. Frequency of Reduced Modals in Different Text Categories

\begin{tabular}{llll}
\hline Modals & Fiction & Academic & News \\
gonna & 22 & 0.55 & 8 \\
gotta & 9 & 0.24 & 3 \\
wanna & 4 & 0.16 & 1 \\
\hline
\end{tabular}

In table 5, it is observed the visible differences of frequency in distinguished text categories. Reduced modals, based on the findings, are more commonly found in fiction (e.g., gonna is 22 times per one million words) than in news texts (e.g., gonna is 8 times per one million words), and between news texts and academic texts, it is more commonly used in news text (e.g, gonna in academic texts is 0.55 times per one million words). In other words, fiction has the highest usage frequency of reduced modals compared to academic and news texts. Academic texts seem to avoid the use of reduced modals, while we can find the use of reduced modals in news text, even though the number is small, but it is still higher than academic texts. Colloquialization also influences the use of modals in a particular text; texts that can be influenced with colloquial style might use reduced modals more frequently as seen in fiction texts. Academic texts, however, seem to avoid reduced forms as reduced forms are not the characteristics of standard language. As for news texts, the use of reduced modals are in between fiction and academic texts which shows news texts are primarily the 'combination' of fiction and academic as they are not too strict with the use of standard language and attempt to be close to the readers.

\section{Factors Triggering the Dynamic of Use}

Given the findings discussed previously, it is important to note that the use of reduced modals is quite dynamic across different period of time, regions, mediums, and text categories. In the last centuries (comparing ARCHER and COCA), the use of reduced modals is significantly growing, indicating the increasing need of language users to use the reduced forms in daily communication. The number of use of reduced modals synchronically also marks the prominence of reduced forms as they are found in any countries, 
medium, and text categories, although they are more frequent in English language spoken in the US, in spoken English, and in fiction texts.

To get profound analysis on why reduced modals are dynamic, it is necessary to consider the nature of each variable being compared. Different frequencies of reduced modals described in the comparison of spoken and written English are connected with the nature of the medium. Spoken language is, but not always, identical to colloquial style. Reduced forms are the results of speakers' effort to minimize sound production correspond to principle of least effort (Zipf, 1949). In accordance with Zipf's theory, indeed language works according to economy principle stating that grammar should be economical so it can be learnt easier and faster (van Gelderen, 2004; van Gelderen, 2011). To achieve this, grammar must prioritize the necessary mechanism in their system to be able to work as efficient as possible. In line with van Gelderen, Poedjosoedarmo (2006) argues that grammar should be brief (e.g., no redundant forms) for the efficiency of message delivery. From Zipf to van Gelderen and Poedjosoedarmo, it is noted that language system-as well as language use - should be concise but powerful.

In relation to language use, it is therefore unsurprising to find the use of shortened forms, especially in daily use of language. In daily speaking activity, language users tend to be more practical, efficient, and economical, by using reduced forms, instead of the full forms. In other words, reduced forms are the style of daily use of language, or also linked with colloquial language. As defined in Oxford Dictionary of English, colloquial is language used in ordinary or familiar conversation. More linguistically, it is defined as a term applied to vocabulary and grammar typical of informal style (Brown and Miller, 2013).

In written medium of language use, frequency of reduced modals is not as frequent as in the spoken one. It is due to the influence of colloquialization in written medium of language use is relatively lower than in spoken language. In addition, written language is not spontaneous and provides longer space so that reduced forms are unnecessary. On the contrary, spoken language must be as efficient as possible, hence reduced modals are preferable to some extent. In fact, some written forms of language nowadays are actually more speech-like. Affected by the advancement of technology, there are now messaging platforms that have the characteristics of spoken language, but use written medium, e.g., WhatsApp, Line, WeChat, etc. These messaging applications provide their users with two-way interactions, enable the users to have a conversation to the interlocutors in written form. In this sort of communication, the style is more colloquial, even though it happens in written form.

Regarding text categories, comparing fiction texts, academic texts, and news texts, it is undoubtedly obvious that fiction is more colloquial. In fiction, there are some dialogues created by the authors to build up the story and to strengthen the traits of the characters. This corresponds to Leech and Short (2007) who claim that the language in fiction is used manipulatively to 
construct the imaginary world. In dialogues the authors are allowed to use speech style in which they are colloquial style. This is important to make the narrative more realistic and closer to the reader of the fiction. It is noted that colloquialization holds crucial role in the choice of reduced modals in a particular discourse. In academic texts which standard language rules, the frequency of phonetically reduced modals is extremely low (e.g., gonna occurs 0.55 times per one million words). Furthermore, reduced modals belong to semi-modal (or quasi-modal) category in which semi-modals are closely associated with colloquialization (Leech, et al., 2009). Hence the use of phonetically reduced modals is quite rare in academic context.

According to the findings, different frequencies of reduced modals also occur in different region of English. It marks the language used in each region as being a regional dialect. This variety is possible because the society is complex, having different background, delivering different needs using different ways. Therefore, we can notice different frequencies of phonetically reduced modals in which they have the highest frequency in the US English language (or American English). Following Collins (2014), American English is more adjustable to changes, opposite to British English that is more conservative. Not only is American English more adjustable, but it also plays its role as leader of changes as known in the term 'Americanization' which is no longer bizarre. Crystal (2003) says that Americanization includes the influence of American English to other English varieties (world Englishes) since it has the biggest number of English speakers across the globe. It is appealing that although world Englishes is developing, but the vigorous influence of American English worldwide is inevitable. From the elaboration, it is then evident that basically language use is dynamic and varied since the society (i.e. the language user) is complex and dynamic as well. In other words, theoretically, language use is phonetically simplified due to efficiency and daily basis usage; and it is sociolinguistically colloquialized as the primary medium of language is speaking.

\section{CONCLUSION}

To sum up, there are several points that have to be taken into account. Over the past decades, the use of reduced modals is sharply increasing, as shown by the comparison of ARCHER and COCA. Related to the use of phonetically reduced modals in different regions, reduced modals more frequently used in the US than in four other English-speaking countries under study. It is because English language spoken in the US is more adaptive to changes, including to phonetic changes of modals. The results of this study also show reduced modals in spoken language are more frequently occur than in written language. Alike different regions and different medium of discourse, different frequency can be observed in different text categories. Based on the findings, reduced modals used in fiction texts are the highest compared to academic texts and news texts. Meanwhile, academic texts rarely use reduced modals because this text category must follow the standard language. Reduced forms are known to be more colloquial but less standard. This phonetic 
reduction follows the rules of economy principle in language structure and language use, in line with principle of least effort proposed by Zipf (1949). In general, the use of phonetically reduced modals is affected by colloquialization; as for discourse context, it concerns with which type of text that is more colloquial that allows the use of reduced modals.

\section{REFERENCES}

Adepoju, Olalakan Tunde. (2016). Discourse functions of Will and Shall in Christian prayers. International Journal of Humanities and Cultural Studies, Vol. 2, Issue 4: 1096-1107.

Baker, Paul. (2010). Sociolinguistics and corpus linguistics. Edinburgh: Edinburgh University Press.

Biber, Douglas, Susan Conrad. (2009). Register, genre and style. Cambridge: Cambridge University Press.

Biber, Douglas. (2004). "Modal use across registers and time". Curzan, Anne and Kimberly Emmons (ed.). Studies in the history of the English language II. Berlin/New York: Mouton de Gruyter.

Biber, Douglas, Stig Johansson, Geoffrey Leech, Susan Conrad, Edward Finnegan. (1999). Longman grammar of spoken and written English. London: Longman.

Brezina, Vaclav, Tony McEnery, and S. Wattam. (2015). Collocations in context: A ew perspective on collocation networks. International Journal of Corpus Linguistics, 20(2), 139-173.

Brezina, Vaclav. (2018). Statistics in corpus linguistics. Cambridge: Cambridge University Press.

Brinton, Laurel J. (1991). The origin and development of quasimodal have to in English. Workshop The Origin and Development of Verbal Periphrases, $10^{\text {th }}$ International Conference on Historical Linguistics (ICHL 10). Amsterdam, 16 August 1991.

Brown, Keith, James Edward Miller. (2013). The Cambridge dictionary of linguistics. Cambridge: Cambridge University Press.

Bussmann, Hadumod. (1998). Routledge dictionary of language and linguistics. London: Routledge. 
Chapin, P.G. (1973). Quasi-modals. Journal of Linguistics, 9: 1—9.

Coates, B., and Geoffrey Leech. (1980). The meanings of the modals in modern British and American English'. York Papers in Linguistics 8, 23-34

Coates, Jennifer. (1983). The semantics of the modal auxiliaries, Croom Helm, London and Canberra.

Collins, Peter. (2009). Modals and quasi-modals in English. Amsterdam: Rodopi.

Collins, Peter. (2014). Quasi-modals and modals in Australian English. Journal of English Linguistics, 42 (1): 7-30.

Crystal, David. (2003). English as a global language. Cambridge: Cambridge University Press.

Davies, Mark. (2008). The Corpus of Contemporary American English (COCA): 560 million words, 1990-present. Available online at https://corpus.byu.edu/coca/

de Haan, Ferdinand. (2012). The relevance of constructions for the interpretation of modal meaning: The case of must. English Studies, 93 (6): 700-728.

Facchineti, Roberta. (2000). "The modal verb shall between grammar and usage in the nineteenth century". Kastovsky, Dieter and Arthur Mettinger (ed.). 2000. The history of English in a social context. Berlin: Mouton de Gruyter. 115-134.

Francis, W. Nelson, Henry Kučera. (1982). Frequency analysis of English usage: lexicon and grammar. Boston: Houghton Mifflin.

Halliday, M.A.K. (1990). Spoken and written language. Geelong, Vic.: Deakin University Press.

Hardjanto, Tofan Dwi. (2016). Hedging through the use of modal auxiliaries in English academic discourse. Humaniora, 28 (1): 37-50.

Holmes, Janet. (1988). Doubt and uncertainty in ESL textbooks. Applied Linguistics, Vol. 9(1): 21-44.

Huddleston, R. D. (197I). The sentence in written English: A syntactic study based on an analysis of scientific texts. Cambridge: Cambridge University Press. 
Huddleston, R. D. (1976). Some theoretical issues in the description of the English verbs. Lingua 40: 331-383.

Jakobson, Roman. (1980). Child language aphasia and language universals. The Hague: Mouton Publishers.

Kachru, Braj B. 2008. World Englishes in world contexts. H. Momma and M. Matto (ed.) A companion to the history of the English language, Chichester, UK: Wiley-Blackwell.

Kennedy, Graeme. (1992). Preferred way of putting things with implications for language teaching. J. Svartvik (ed.). Directions in corpus linguistics. Proceedings of the Nobel Symposium 82, Stockholm, 4-8 Agustus 1991. Berlin: Mouton de Gruyter.

Kennedy, Graeme. (1998). An introduction to corpus linguistics. London: Longman.

Krug, Manfred. (2000). Emerging English modals: A corpus-based study of grammaticalization. Berlin: Mouton de Gruyter.

Leech, Geofrrey, Michael H. Short. (2007). Style in fiction: A linguistic introduction to English fictional prose. London: Longman.

Leech, Geoffrey, Marianne Hundt, Christian Mair, Nicholas Smith. (2009). Change in contemporary English. Cambridge: Cambridge University Press.

Lorenz, David, (2013). Semi-modal contractions in English: Emancipation through frequency. Dissertation. Freibur University.

Lyons, John. (1977). Semantics: Volume II. Cambridge: Cambridge University Press.

Macfarlan, Alice. (2013). "Folklinguistic explorations of modals and quasimodals in Australian Englishes". Gawne, Lauren and Jill Vaughan (Ed.). Selected Papers from the $44^{\text {th }}$ Conference of the Australian Linguistics Society.

Machová, Dagma. (2015). The degree of grammaticalization of gotta, gonna, wanna, and better: A corpus study. Topic in Linguistics, issue 15.

Millar, Neil. (2009). Modal verbs in TIME - frequency changes 1923-2006. International Journal of Corpus Linguistics 14 (2): 191-220. 
Oktavianti, Ikmi Nur. (2016). Quasi-modals in British and American English. Lingua Scientia. 8 (2): 257-272.

Palmer, F.R. (2001). Mood and modality. Cambridge: Cambridge University Press.

Payne, Thomas E. (2011). Understanding English grammar. Cambridge: Cambridge University Press.

Perkins, Michael. (1982). The core meanings of the English modals. Journal of Linguistics 18 (2): 245-273.

Poedjosoedarmo, Soepomo. (2006). Perubahan tata bahasa: Penyebab, proses dan akibatnya. Unpublished. Universitas Sanata Dharma, Yogyakarta.

Pullum, G., Wilson, D. (I977). Autonomous syntax and the analysis of the auxiliaries. Language 53.74I-788.

Quirk, Randolph, Sidney Greenbaum, Geoffrey Leech, Jan Svartvik. (1985). A comprehensive grammar of the English language. London: Longman.

Rubinstein, Aynat. (2012). Roots of modality. Dissertation. Amherst, MA: University of Massachusetts Amherst.

Seggewiß, Friederike. (2012). Current change in the English modals. Dissertation. Freiburg: Universität Freiburg.

van Gelderen, Elly. (2004). Grammaticalization as economy. Amsterdam: John Benjamins Publishing.

van Gelderen, Elly. (2011). The linguistic cycle: language change and the language faculty. Oxford: Oxford University Press.

Warner, Anthony R. (2009). English auxiliaries: structure and history. Cambridge: Cambridge University Press.

Zipf, George. (1949). Human behaviour and the principle of least effort: An introduction to human ecology. Cambridge, MA: Addison-Wesley Press, Inc.

\section{List of Corpora}

COCA : https://www.english-corpora.org/coca/

GloWbe : : https://www.english-corpora.org/glowbe/ 


\begin{tabular}{|c|c|}
\hline ARCHER & : https://cqpweb.lancs.ac.uk \\
\hline LOB & : http://www.helsinki.fi/varieng/CoRD/corpora/LOB/ \\
\hline Brown & : \\
\hline
\end{tabular}

\section{Corpus tool:}

Lancsbox : http://corpora.lancs.ac.uk/lancsbox/index.php

\section{Dictionary:}

Oxford Dictionary of English, installed in MacBook Air 2014. 